\title{
Manejo do dinheiro pelo casal e infidelidade financeira
}

\section{Management of money by the couple and financial infidelity}

\author{
Gestión de dinero por la pareja e infidelidad financiera
}

\section{Jeniffer Harth*}

Universidade do Vale do Rio dos Sinos - UNISINOS, São Leopoldo, Rio Grande do Sul, Brasil

\section{Clarisse Pereira Mosmann**}

Universidade do Vale do Rio dos Sinos - UNISINOS, São Leopoldo, Rio Grande do Sul, Brasil

\section{Denise Falcke***}

Universidade do Vale do Rio dos Sinos - UNISINOS, São Leopoldo, Rio Grande do Sul, Brasil

\begin{abstract}
RESUMO
O manejo do dinheiro constitui-se como um dos principais motivos de conflito conjugal. Dessa forma, esse artigo teve como objetivo investigar o manejo do dinheiro pelo casal e as situações de infidelidade financeira. Realizou-se um estudo quantitativo com delineamento descritivo, comparativo e correlacional. Participaram 143 casais, casados oficialmente ou morando juntos, entre 19 e 81 anos. Aplicou-se dois questionários, um sociodemográfico e um sobre manejo do dinheiro. Foram feitas análises estatísticas descritivas e inferenciais. Os resultados revelaram que $58 \%$ utiliza o sistema de gestão compartilhada do dinheiro. A maioria $(93,5 \%)$ afirma nunca ter cometido situações de infidelidade financeira. Ao contrário de estudos prévios, não foram evidentes conflitos significativos em relação ao manejo do dinheiro e sim associação entre infidelidade financeira e renda do casal.

Palavras-chave: casal, finanças, relacionamento conjugal, conflito conjugal.
\end{abstract}

\begin{abstract}
The management of money constitutes one of the main reasons for marital conflict. This paper aimed to investigate the ways couples handle the money and the situations of financial infidelity. A quantitative study with a descriptive, comparative and correlational design was conducted. 143 officially married or living together couples participated. Ages ranged between 19 and 81 years. Two questionnaires were applied, one of sociodemographic data and a questionnaire about management of money. A descriptive and inferential statistics analysis was made. The results revealed that $58 \%$ of participants shared management of money. The majority
\end{abstract}


(93.5\%) indicated that they have never committed financial infidelity. Contrary to previous studies, the results showed no significant conflict regarding the handling of money, but association between financial infidelity and income of the couple.

Keywords: couple, finance, marital relations, marital conflict.

\section{RESUMEN}

La gestión del dinero constituye uno de los principales motivos de conflicto marital. En vista de eso, este artículo ha tenido como objetivo investigar la gestión del dinero por la pareja y las situaciones de infidelidad financiera. Se realizó un estudio cuantitativo con un diseño descriptivo, comparativo y correlacional. Participaron 143 parejas oficiales o que viven juntas, entre 19 y 81 años. Se aplicó dos cuestionarios, uno sociodemográfico y uno acerca de la administración del dinero. Análisis estadísticos descriptivos e inferenciales fueran realizados. Los resultados revelaron que $58 \%$ utiliza un sistema compartido de gestión de dinero. La mayoría $(93,5 \%)$ afirmó nunca haber cometido infidelidad financiera. Contrariamente a los estudios previos, no se identificó significativos conflictos sobre el dinero pero asociación entre la infidelidad financiera y la situación financiera de la pareja.

Palabras clave: pareja, finanzas, relaciones maritales, conflicto marital.

\section{Introdução}

O dinheiro já foi reconhecido em pesquisas prévias como um dos principais motivos de conflito conjugal (Mosmann \& Falcke, 2011; Papp, Cummings, \& Goeke-Morey 2009). Mais do que a quantidade de dinheiro disponível, os estilos de gerenciamento financeiro são percebidos como um fator importante na convivência conjugal (Pahl, 1989). Quatro categorias de gerenciamento do dinheiro foram identificadas por Pahl (1989): Sistema de gerenciamento total dos gastos, em que todo o ganho salarial é gerenciado por um único cônjuge, exceto os gastos pessoais do parceiro; Sistema de gerenciamento por mesada ou pensão, em que um dos cônjuges é o principal provedor financeiro, fornecendo um valor para as despesas da casa e mantendo um valor não revelado para outros gastos, inclusive seus gastos pessoais; Sistema de gestão compartilhada do dinheiro, em que ambos os cônjuges têm acesso ao dinheiro e ambos têm um papel ativo na tomada de decisões financeiras e Sistema de gestão independente do dinheiro, em que cada cônjuge tem o controle individual sobre sua renda e compromissos individuais com as despesas da casa.

Os casais usam diferentes estilos de gerenciamento do dinheiro, que podem funcionar ou resultar em conflitos entre o casal, podendo gerar estresse (White \& Rogers, 2000) e diminuir a intimidade do casal (Atwood, 2012; Hardie \& Lucas, 2010; Lauer \& Yodanis, 2011). Um estudo realizado no Sul da Inglaterra (Burgoyne, Reibstein, Edmunds, \& Dolman, 2007), com 42 casais em primeira união, buscando capturar as diferentes experiências e perspectivas 
referentes ao gerenciamento do dinheiro, ilustra a funcionalidade e transição de um tipo de gerenciamento para outro. Esse estudo mostrou que a maioria dos casais mantinha uma gestão independente do seu dinheiro antes do casamento e passou a adotar sistemas coletivos de gerenciamento após o primeiro ano do mesmo, o que contribui para a qualidade do relacionamento.

O planejamento das despesas de um casal é algo bastante difícil, pois - dinheiro tem um significado particular para cada pessoa, especialmente considerando que cada cônjuge possui diferentes formas de pensar sobre a vida, os relacionamentos e também sobre o dinheiro (Xavier, 2013). Sendo assim, torna-se quase impossível a realização de um planejamento que seja totalmente do agrado de ambos os cônjuges (Archuleta, 2013; Cezar-Ferreira, 2007). Muitos casais têm lutado contra problemas financeiros de diversas naturezas, possivelmente agravados por constantes crises econômicas, desemprego e redução da renda (Moore \& Palumbo, 2009), entre outros motivos. Em nível pessoal e relacional, características de personalidade, hábitos arraigados e diferenças de estilo de gerenciamento financeiro entre os cônjuges (Falconier \& Epstein, 2010) podem desencadear conflitos relacionados às finanças, o que pode gerar angústia (Robila \& Krishnakumar, 2005), ainda mais se a contribuição financeira de ambos para as despesas da casa for muito diferenciada (Mills, Grasmick, Morgan, \& Wenk, 1992).

As mulheres têm se tornado cada vez mais independentes financeiramente, inclusive tendo crescido o número de mulheres que provêm financeiramente o casal, como mostra a Pesquisa Nacional por Amostra de Domicílios - PNAD, do Instituto Brasileiro de Geografia e Estatística - IBGE, que ressalta que, de 2009 a 2011, 0 número de famílias em que a mulher é a principal provedora financeira subiu de $35,1 \%$ para $37,4 \%$ (IBGE, 2011). Ainda assim, é mais comum que o homem ainda seja o principal provedor financeiro em um relacionamento (Perguer, 2010), levando-o a ter maior influência sobre o dinheiro, inclusive sem ser questionado sobre seus gastos pessoais (Burgoyne, et. al., 2007). Mesmo as mulheres mostrando maior independência na sua atitude com o dinheiro, elas tendem a ser mais precavidas e sentem-se inseguras quanto ao que fazer com o mesmo sem o auxílio do companheiro (Perlin, 2006). Com isso, nota-se que o dinheiro tem sido, além de um objeto de poder financeiro, também um objeto com significado emocional e, devido a isso, pode influenciar o comportamento das pessoas (Rose \& Orr, 2007), inclusive na manutenção ou questionamento dos tradicionais papéis de gênero.

Indiferente de quem é o provedor financeiro, o dinheiro está, em muitos casos, associado ao poder, fazendo com que aquele que tem sua posse sinta-se em posição superior (Cardoso \& Lima, 2006). Nesse sentido, há um estudo realizado por Perlin (2006), com cinco 
casais, visando identificar e discutir as dimensões que afetam a satisfação conjugal no casamento de duplo trabalho. A autora identificou que, na intenção de manter a submissão da mulher no relacionamento, o homem pode querer torná-la dependente financeiramente dele.

Costa (2007) compreende que a maneira como os cônjuges lidam com o dinheiro na relação é um reflexo da maneira como eles amam seu parceiro. A associação entre amor e dinheiro também foi examinada em uma pesquisa realizada com 1.597 casais coabitantes da Suécia e Noruega (Wiik, Bernhardt, \& Noack, 2010). Tanto o dinheiro quanto o amor aparecem como fatores importantes na decisão pelo casamento, sendo que as mulheres apresentaram maior preocupação com o compromisso na união como um fator positivo na intenção de casar, enquanto que os homens foram mais influenciados tanto pela sua renda quanto da parceira, além da sua própria educação.

Outra pesquisa, realizada com 115 adultos coabitantes, de classe média baixa, moradores de Ohio (Smock, Manning, \& Porter, 2005), teve o objetivo de explorar como os aspectos econômicos podem influenciar na decisão pelo casamento. O resultado indicou que as pessoas que coabitam acreditam que o casamento deve ocorrer depois que algo já tenha mudado no relacionamento, nesse caso, o status financeiro.

A partir das pesquisas de Wiik et. al. (2010) e Smock, Manning e Porter (2005) também é possível hipotetizar que, se o dinheiro é um fator importante na decisão pelo casamento, provavelmente continuará a sê-lo durante o mesmo, podendo, o seu manejo, estar relacionado com a qualidade conjugal (Boyle, 2012). Essa conjuntura torna-se ainda mais possível levando em consideração uma pesquisa realizada na Grã-Bretanha, com 1.292 pessoas casadas ou em um relacionamento coabitante (Vogler, Lyonette, \& Wiggins, 2008), que mostrou que os homens e mulheres estavam mais insatisfeitos com a vida familiar, e em geral, quando tomavam decisões individuais sobre seus gastos em relação àqueles que tomavam decisões conjuntas. Corroborando esses achados, Archuleta (2013) aponta que os valores em comum do casal sobre dinheiro e objetivos compartilhados podem promover maior qualidade conjugal.

Nesse sentido, o dinheiro parece ter um importante papel nas relações conjugais, seja na direção de incrementar o relacionamento, quando há um manejo adequado, ou como um dispositivo que facilmente ocasiona conflitos entre os cônjuges. Porém, os resultados preliminares de uma pesquisa com o objetivo de conhecer os diferentes arranjos conjugais da atualidade (Féres-Carneiro, Ziviani, \& Magalhães, 2011) têm demonstrado que o dinheiro talvez não seja o grande vilão nas relações conjugais. Das 36 entrevistas analisadas, em apenas quatro delas o dinheiro foi citado como um problema na 
relação, estando associado à cobrança e ao controle do cônjuge, o que diz respeito muito mais ao manejo que os mesmos fazem do dinheiro do que à quantidade do mesmo.

Atualmente, dentro da temática do dinheiro, identifica-se o uso do termo "infidelidade financeira", especialmente por meios não acadêmicos. Essa nomenclatura, utilizada em dados de pesquisa de mercado (National Endowment for Financial Education, 2010), se refere à ideia de traição financeira, quando um dos cônjuges mente sobre questões relacionadas às finanças do casal. Geralmente são situações relacionadas à omissão ou alteração de informações sobre o valor dos gastos e dívidas, contas bancárias e até mesmo outras fontes de renda. Embora esse conceito tenha se popularizado através da mídia, não foram localizados estudos científicos que envolvam esse descritor, apenas pesquisas de cunho informal. Nesse sentido, torna-se relevante que as situações relacionadas ao manejo financeiro do casal investiguem situações que possam estar relacionadas ao conceito de infidelidade financeira.

A partir dos estudos sobre o tema, parece evidente que o dinheiro mobiliza questões psicológicas importantes, além de ser um objeto inevitavelmente presente na vida a dois. Partindo desses pressupostos, este artigo teve como objetivo geral investigar 0 manejo do dinheiro pelo casal. Mais especificamente, buscou-se conhecer as categorias de manejo do dinheiro utilizadas pelos casais e as situações de infidelidade financeira que possam ter ocorrido durante o relacionamento conjugal.

\section{Método}

\subsection{Delineamento}

Esse é um estudo quantitativo, com delineamento descritivo, comparativo e correlacional, que buscou caracterizar o manejo do dinheiro pelo casal e evidenciar associações ou diferenças conforme as variáveis sociodemográficas.

\subsection{Participantes}

A pesquisa foi realizada com 143 casais, casados oficialmente ou em união estável. Primeiramente considerou-se excluir da pesquisa todos os casais que tivessem filhos $(n=97)$, mas as análises estatísticas demonstraram não haver diferenças significativas entre os casais com ou sem filhos, participantes dessa pesquisa, com exceção apenas no que se refere a um maior gasto em saúde pelos casais com filhos $(t=-2,353 ; p=0,019)$. Assim, optou-se por realizar as análises considerando a amostra completa. 
Sendo assim, compuseram a amostra 143 casais com idades que variaram de 19 a 81 anos $(m=41,23 ; d p=12,77)$, residentes na região metropolitana de XXX. Do total, $60,6 \%$ eram casados oficialmente e $39,4 \%$, moravam juntos. A maioria possuía filhos $(68,1 \%)$, ensino médio $(44,2 \%)$ e trabalhava $(83,9 \%)$. Quanto à situação de trabalho, 53,8\% possuíam vínculo empregatício, 30,1\% eram autônomos, 8,6\% aposentados ou pensionistas, 3,9\% exerciam atividade no lar, $2,2 \%$ eram estudantes e $1,4 \%$ estavam desempregados. A média de renda pessoal dos homens foi significativamente maior do que das mulheres, sendo $R \$ 4.195,96$ para os homens e $\mathrm{R} \$ 2.828,74$ para as mulheres $(\mathrm{t}=-2,572$; $p=0,011)$.

\subsection{Instrumentos}

Foram utilizados como instrumentos um questionário de dados sociodemográficos e um questionário sobre o manejo do dinheiro. $O$ questionário de dados sociodemográficos coletou informações como idade, escolaridade, tempo de casamento, situação ocupacional e renda, buscando caracterizar a amostra do estudo. Com relação ao manejo do dinheiro, como não foram localizados questionários validados a respeito do construto, para essa pesquisa foi elaborado um questionário com versão masculina e feminina, baseado na revisão de literatura e em pesquisas já realizadas sobre o tema. Inicialmente, o questionário sobre manejo do dinheiro foi elaborado de forma a contemplar duas dimensões desse manejo, sendo a primeira uma dimensão descritiva da situação financeira do casal, com questões como o conhecimento sobre a renda do cônjuge, quem costuma contribuir mais nas despesas da casa, quais são as prioridades de gastos do casal, entre outros. A segunda dimensão do manejo do dinheiro abordada nesse questionário dizia respeito à infidelidade financeira, contemplando questões como terem cometido algum gasto ou compra escondido do(a) parceiro(a), terem escondido uma conta bancária ou terem pego dinheiro do(a) parceiro(a) sem que ele(a) soubesse, além de questões sobre as consequências da infidelidade financeira cometida pelos cônjuges. O questionário foi submetido a cinco juízes que avaliaram a pertinência e adequação dos itens ao construto que se pretendia investigar, tendo obtido parecer favorável.

A partir do estudo piloto realizado com 30 casais, foi possível identificar que os dados descritivos demonstraram capacidade de caracterizar a amostra do estudo. Além disso, o coeficiente Alpha de Cronbach obtido para a dimensão de infidelidade financeira foi de 0,84 , considerado bastante adequado para a manutenção do instrumento na forma como foi construído. Todavia, constatou-se uma dificuldade em categorizar os casais conforme o tipo de 
gerenciamento do dinheiro, como descrito por Pahl (1989). Nesse sentido, optou-se por incluir uma terceira dimensão do manejo do dinheiro no instrumento, que diz respeito a essas categorias de gerenciamento, sendo elas: gerenciamento total do dinheiro, gerenciamento por pensão ou mesada, gerenciamento compartilhado e gerenciamento individual do dinheiro do casal. Essa dimensão foi analisada através de uma questão em que os casais optaram por uma de quatro alternativas, aquela que melhor descrevia a forma como eles gerenciavam o dinheiro do casal.

Com essas três dimensões acerca do manejo do dinheiro: descrição da situação financeira do casal, infidelidade financeira e categorias de gerenciamento do dinheiro, buscou-se mapear a forma como os cônjuges gerenciam seu dinheiro. O Alpha de Cronbach obtido ao final do estudo foi de 0,895, indicando a confiabilidade do instrumento.

\subsection{Procedimentos de coleta de dados}

Após aprovação no Comitê de Ética da Universidade do Vale do Rio dos Sinos (parecer número 11/129), os participantes foram contatados por conveniência e os questionários foram aplicados em local escolhido pelo casal, de forma simultânea, mas separadamente, para que um não soubesse das respostas do outro. Após o contato com os participantes, foi feito um rapport explicando os objetivos da pesquisa e a eles foi solicitado que assinassem o Termo de Consentimento Livre e Esclarecido (TCLE), garantindo que estavam cientes de sua participação nessa pesquisa.

\subsection{Análise dos dados}

Os dados foram trabalhados estatisticamente através de análises descritivas, para a caracterização do manejo do dinheiro pelo casal. Comparações entre grupos foram realizadas através do teste $t$ de Student ou de análise de variância e as associações entre variáveis foram analisadas através de correlação de Pearson.

\section{Resultados}

A maioria dos participantes $(83,9 \%)$ disse ter conhecimento do quanto seu parceiro ganha e, quando questionados sobre qual seria a renda do parceiro, ao compararmos com o valor expresso pelo próprio sujeito, observou-se um moderado nível de concordância $(K=0,54 ; p=0,021)$, indicando que os cônjuges possuem informações que se aproximam do valor exato declarado pelo companheiro. Um total de $86,7 \%$ dos participantes considerou a renda familiar 
suficiente para viverem e pouco mais da metade $(55,4 \%)$ referiu que ambos os cônjuges contribuem igualmente nas despesas da casa, sendo ainda o homem, apesar de pouca diferença (50,4\% em relação a $49,6 \%$ das mulheres), aquele que mais contribuía. Essa mínima diferença talvez justifique o fato de que $90,9 \%$ dos participantes consideraram que seu cônjuge não deveria contribuir mais do que contribuía no momento.

Com relação aos gastos do(a) parceiro(a), 86\% dos participantes referiram concordar com a maioria dos gastos dele(a). Apesar disso, $20,9 \%$ referiram que costumam brigar quando há um gasto indevido por parte do(a) parceiro(a). Os cônjuges relataram, em sua maioria $(67,5 \%)$, que ambos controlam o dinheiro do casal e, nos casos em que esse controle é separado, as mulheres são as que mais controlam o dinheiro, com $17,3 \%$, contra $15,2 \%$ dos homens. Um percentual expressivo de $83,5 \%$ dos participantes diz receber ajuda de outras pessoas na renda familiar, tais como pais, sogros, avós e filhos.

Os participantes tiveram de enumerar de 1 a 9 suas prioridades de gastos, dentre algumas opções estipuladas no questionário. O quesito que obteve maior pontuação como prioridade 1 foi a alimentação, em que a maioria $(50,2 \%)$ mencionou como o item que mais impacta no orçamento doméstico. Quanto às despesas da casa (aluguel, condomínio, água e luz), 33,2\% a estipularam como segunda prioridade. Os interesses pessoais apareceram como maior prioridade para apenas $0,4 \%$ dos participantes, tendo obtido maior índice na oitava posição $(26,1 \%)$. Um percentual de $31,3 \%$ estipulou os investimentos como prioridade número oito e a opção outros foi a mais pontuada como última prioridade $(61,5 \%)$, indicando que os itens citados no questionário contemplavam os principais gastos.

No relacionamento atual, $57,5 \%$ dos participantes disseram já ter juntado suas finanças com o companheiro alguma vez, sendo que $18,2 \%$ juntaram as finanças em conta corrente, $15,5 \%$ no cartão de crédito, $14,2 \%$ na poupança e $6,1 \%$ juntaram dinheiro. Verificou-se ainda que $10,1 \%$ dos participantes indicaram que teriam juntado outro tipo de finança (bens, investimentos e dívidas) e 35,8\% indicaram já terem juntado as finanças em mais de uma das opções anteriores. Ainda que $42,5 \%$ dos participantes nunca tenham juntado suas finanças com o(a) companheiro(a), a maioria deles $(79,3 \%)$ planejava seus gastos em conjunto. 
Tabela 1

Percentual de respostas sobre indicativos de infidelidade financeira

\begin{tabular}{l|c|c|c|c}
\hline \multicolumn{1}{c|}{ Itens } & Nunca & $\begin{array}{c}\text { Rara- } \\
\text { mente }\end{array}$ & $\begin{array}{c}\text { Às } \\
\text { vezes }\end{array}$ & $\begin{array}{c}\text { Frequen- } \\
\text { temente }\end{array}$ \\
\hline $\begin{array}{l}\text { Escondi dinheiro do meu } \\
\text { companheiro }\end{array}$ & 77,0 & 14,7 & 7,9 & 0,4 \\
$\begin{array}{l}\text { Escondi um pequeno gasto do } \\
\text { meu companheiro }\end{array}$ & 58,1 & 28,2 & 12,3 & 1,4 \\
$\begin{array}{l}\text { Escondi um grande gasto do } \\
\text { meu companheiro }\end{array}$ & 88,1 & 8,3 & 3,2 & 0,4 \\
$\begin{array}{l}\text { Escondi um extrato bancário } \\
\text { do meu companheiro }\end{array}$ & 84,8 & 10,9 & 3,6 & 0,7 \\
$\begin{array}{l}\text { Escondi uma conta bancária do } \\
\text { meu companheiro }\end{array}$ & 92,8 & 4,3 & 2,9 & 0 \\
$\begin{array}{l}\text { Menti ao meu companheiro } \\
\text { sobre algo relacionado às } \\
\text { finanças a }\end{array}$ & 77,5 & 16,7 & 5,1 & 0,7 \\
$\begin{array}{l}\text { Menti ao meu companheiro } \\
\text { sobre uma divida que eu devia }\end{array}$ & 81,9 & 13,0 & 2,9 & 2,2 \\
$\begin{array}{l}\text { Menti ao meu companheiro } \\
\text { sobre quanto dinheiro eu } \\
\text { ganho/ ganhava }\end{array}$ & 89,5 & 7,6 & 2,2 & 0,8 \\
$\begin{array}{l}\text { Peguei dinheiro do meu } \\
\text { companheiro sem ele saber }\end{array}$ & 93,5 & 5,0 & 0,4 & 1,1 \\
\hline
\end{tabular}

Conforme a tabela 1, observa-se que a grande maioria dos participantes relata nunca ter cometido qualquer uma das situações de infidelidade financeira mencionadas, com maior expressão em $93,5 \%$ que afirmam nunca terem pegado dinheiro do(a) parceiro(a) sem que ele(a) soubesse. Os participantes que já cometeram alguma infidelidade financeira relataram, em sua maioria, que foram raras às vezes em que isso aconteceu, sendo que a situação mais comum foi esconder um pequeno gasto do(a) parceiro(a) $(28,2 \%)$.

Considerando as situações de infidelidade financeira analisadas, verificou-se que não houve diferença entre os sexos $(p=0,454)$, a situação conjugal $(p=0,863)$, a idade $(p=0,258)$ ou o tempo de relacionamento $(p=0,330)$. As situações de infidelidade financeira somente se correlacionaram negativa e significativamente com a renda pessoal $(r=-0,131 ; p=0,045)$, indicando que quanto maior a renda, menor a frequência de infidelidade financeira.

Além dos participantes responderem sobre situações de infidelidade financeira cometida por eles próprios, também foram questionados sobre a possibilidade de seus companheiros terem cometido essas situações. A tabela a seguir apresenta os dados a respeito da percepção dos participantes sobre as atitudes dos cônjuges. 


\begin{tabular}{|c|c|c|c|c|}
\hline & Nunca & $\begin{array}{l}\text { Rara- } \\
\text { mente }\end{array}$ & $\begin{array}{c}\text { Às } \\
\text { vezes }\end{array}$ & $\begin{array}{l}\text { Frequen- } \\
\text { temente }\end{array}$ \\
\hline $\begin{array}{l}\text { Meu companheiro escondeu } \\
\text { dinheiro de mim }\end{array}$ & 80,7 & 11,7 & 6,2 & 1,4 \\
\hline $\begin{array}{l}\text { Meu companheiro escondeu um } \\
\text { pequeno gasto de mim }\end{array}$ & 61,2 & 23,8 & 12,5 & 2,5 \\
\hline $\begin{array}{l}\text { Meu companheiro escondeu um } \\
\text { grande gasto de mim }\end{array}$ & 86,2 & 8,4 & 3,6 & 1,8 \\
\hline $\begin{array}{l}\text { Meu companheiro escondeu um } \\
\text { extrato bancário de mim }\end{array}$ & 88,0 & 7,3 & 2,9 & 1,8 \\
\hline $\begin{array}{l}\text { Meu companheiro escondeu } \\
\text { uma conta bancária de mim }\end{array}$ & 92,6 & 4,1 & 2,2 & 1,1 \\
\hline $\begin{array}{l}\text { Meu companheiro mentiu sobre } \\
\text { algo relacionado às finanças }\end{array}$ & 82,0 & 11,4 & 5,5 & 1,1 \\
\hline $\begin{array}{l}\text { Meu companheiro mentiu sobre } \\
\text { uma divida que ele devia }\end{array}$ & 87,5 & 7,0 & 3,3 & 2,2 \\
\hline $\begin{array}{l}\text { Meu companheiro mentiu sobre } \\
\text { quanto dinheiro ele ganha/ } \\
\text { ganhava }\end{array}$ & 91,2 & 4,8 & 2,6 & 1,4 \\
\hline $\begin{array}{l}\text { Meu companheiro pegou } \\
\text { dinheiro meu sem eu saber }\end{array}$ & 91,9 & 5,5 & 1,5 & 1,1 \\
\hline
\end{tabular}

$\mathrm{Na}$ tabela 2, nota-se que os resultados não mudaram significativamente em relação à tabela anterior, mostrando que os participantes acreditam que seus companheiros, assim como eles mesmos, em sua maioria, nunca cometeram nenhuma situação de infidelidade financeira. Um percentual de $91,9 \%$ dos participantes diz que seu(sua) companheiro(a) nunca pegou seu dinheiro sem que soubesse, mesma situação que esses participantes afirmam, em sua maioria, nunca terem cometido. Entre os participantes que mencionaram que seu(sua) companheiro(a) já cometeu alguma infidelidade financeira, a maioria também relata que raramente isso aconteceu, sendo que $23,8 \%$ afirmam que seu(sua) parceiro(a) já escondeu um pequeno gasto.

Considerando as situações de infidelidade financeira que os participantes avaliaram como tendo sido cometidas por seus parceiros, verificou-se que não houve diferença entre os sexos $(p=0,746)$, a situação conjugal $(p=0,433)$, a idade $(p=0,594)$, $o$ tempo de relacionamento $(p=0,493)$ e a renda $(p=0,195)$.

Os participantes também foram questionados quanto às consequências derivadas de terem acontecido as situações de infidelidade financeira. Dentre os participantes que tinham cometido alguma das situações de infidelidade financeira, $42,4 \%$ referiram que houve uma discussão sobre o assunto, 8,8\% consideraram a possibilidade de divórcio, $8,4 \%$ disseram que passaram a ter menos 
confiança no relacionamento, $7,9 \%$ referiram ter separado suas finanças a partir de então e $7,3 \%$ consideraram que passaram a ter menos intimidade no relacionamento. Ainda considerando possíveis consequências, $28,8 \%$ indicaram não terem se importado com 0 acontecido e $17,4 \%$ não chegaram a conversar sobre o assunto. Mesmo que se trate de uma dificuldade enfrentada pelo casal, a maioria dos participantes também identificou uma consequência positiva a partir do ocorrido, uma vez que $72,2 \%$ consideraram que, após o momento de crise, ficaram mais unidos ou cresceram como casal.

Também foram feitas perguntas sobre diferentes possíveis soluções que o casal tenha adotado após uma situação de infidelidade financeira, sendo referido por $81,7 \%$ que eles resolveram se comunicar mais abertamente sobre as finanças; $27,7 \%$ decidiram manter contas separadas e $31 \%$ referiram ter deixado tudo como estava, ainda que devessem ter mudado. Em contrapartida, muitos participantes manifestaram indiferença à situação ocorrida, pois $50,9 \%$ concordaram que não viram necessidade de mudar e $65,6 \%$ concordaram que isso não é um problema no relacionamento atual. É interessante considerar que a maioria dos participantes revela que 0 parceiro ficou sabendo da situação de infidelidade cometida por ele $(80,6 \%)$ e somente $25,6 \%$ indica ter dúvida se o companheiro cometeu alguma das situações de infidelidade financeira descritas.

Quanto ao gerenciamento financeiro do dinheiro, conforme as categorias estipuladas por Pahl (1989), a maior parte dos participantes $(58 \%)$ mencionou que ambos os cônjuges gerenciam o dinheiro do casal e as despesas da casa. Dos demais, $25 \%$ relataram que mantém suas finanças separadas, da mesma forma como assumem compromissos individuais com as despesas da casa, 13\% afirmaram que apenas um dos cônjuges é responsável pelo gerenciamento total do dinheiro do casal e 4\% disseram que um dos cônjuges destina parte do seu ganho salarial para o(a) companheiro(a) gerenciar as despesas domésticas.

\section{Discussão}

Através da caracterização da amostra, observou-se que, na maior parte dos casais, o sustento familiar é compartilhado por ambos os cônjuges $(55,4 \%)$, ainda que a renda dos homens seja significativamente superior a das mulheres (média de $R \$ 4.195,96$ comparada com média de $\mathrm{R} \$ 2.828,74$ das mulheres), o que também caracteriza os participantes como pertencendo a um nível socioeconômico médio. Percebe-se que os homens são os que mais contribuem nas despesas da casa, mantendo a afirmação feita por Perguer (2010), de que ainda o homem costuma ser o principal 
provedor financeiro em um relacionamento. Todavia, a pouca diferença (50,4\% para os homens e $49,6 \%$ para as mulheres), ao se questionar quem mais contribui com os gastos da casa, reflete os dados do PNAD de 2011, mostrando que cresceu o número de mulheres que provém financeiramente a família (IBGE, 2011), remetendo a uma participação mais igualitária de ambos os cônjuges no sustento familiar e a um comprometimento conjunto em relação às despesas e ao planejamento dos gastos. Nesse sentido, a maioria dos casais parece não ter maiores desentendimentos devido ao planejamento financeiro, uma vez que somente $20,9 \%$ referiram brigar com o parceiro por causa de algum gasto indevido por parte dele, o que parece indicar que a maioria dos participantes respeita as opções de gastos do(a) companheiro(a).

Perlin (2006) mencionou que as mulheres costumam sentirem-se inseguras quanto ao que fazer com o dinheiro sem o auxílio do companheiro, o que não parece ser um problema significativo para as mulheres desse estudo, pois são elas as que mais controlam o dinheiro quando o gerenciamento é feito exclusivamente por um dos membros do casal. No entanto, em sua maioria, os casais participantes fazem o gerenciamento do dinheiro em conjunto e, mesmo aqueles que nunca juntaram suas finanças, também fazem o planejamento dos gastos em conjunto, justificando o fato da maior parte dos casais (58\%) utilizarem um sistema de gestão compartilhada do dinheiro.

As situações de infidelidade financeira e suas consequências, mencionadas neste estudo, de certa forma fazem referência a situações de desacordo do casal em relação ao dinheiro. Nesse sentido, observa-se que raramente os casais participantes tiveram desavenças ou precisaram remanejar seus acordos financeiros, pois a maioria afirma que nunca cometeu uma situação de infidelidade financeira, da mesma forma que acredita que seu(sua) companheiro(a) também nunca o fez. Ainda assim, aqueles que afirmaram ter cometido alguma infidelidade financeira identificam que tiveram algumas consequências devido a isso, sejam elas negativas ou positivas. Uma delas foi o fato do casal ter passado a ter menos intimidade no relacionamento, confirmando os achados de Atwood (2012), Hardie \& Lucas (2010) e Lauer \& Yodanis (2011), que consideram que problemas de ordem financeira podem diminuir a intimidade do casal. Também foi indicado que existiram discussões sobre o acontecido, menos confiança no parceiro, mudança no gerenciamento financeiro e inclusive a possibilidade de divórcio.

Os achados também indicaram que quanto maior a renda dos cônjuges, menor a frequência de situações de infidelidade financeira. Tal pressuposto vai de encontro à literatura que indica que, independentemente da situação financeira, os conflitos com 0 dinheiro se relacionam prioritariamente a forma como o casal 
gerencia as finanças. Na amostra do presente estudo, observou-se correlação negativa entre a renda e as situações de infidelidade financeira cometidas, indicando que quanto menor a renda, maior infidelidade foi observada. Pode-se pensar então que, da mesma forma que o status financeiro é importante na decisão pelo casamento (Smock, Manning, \& Porter, 2005) também pesa na resolução de conflitos relacionados ao dinheiro, possivelmente justificando os baixos índices de infidelidade financeira encontrados neste estudo, devido aos participantes serem de um nível socioeconômico médio.

Observou-se que alguns sujeitos ( $7,9 \%$ dos que cometeram situações de infidelidade) revelaram que passaram a ter uma gestão independente do dinheiro depois de terem cometido alguma situação de infidelidade financeira, ainda que seja a minoria. Nesse caso, a mudança de um sistema de gerenciamento do dinheiro para outro, não se deu pela percepção de comprometimento na relação, como apontado no estudo de Burgoyne et al (2007), mas como solução adotada diante de uma situação de infidelidade financeira.

Ainda como consequência das situações de infidelidade financeira cometidas pelos participantes desse estudo, uma parcela bem significativa deles pareceu indiferente ao fato, como aqueles que não buscaram alguma solução, não sinalizaram consequência pelo fato, alegaram que não viram a necessidade de mudar ou não consideraram isso um problema no relacionamento. Considerando que mais de $80 \%$ referiu que o companheiro descobriu a infidelidade financeira cometida, talvez esse dado demonstre que mesmo entre os casais que tiveram pequenos contratempos em relação às finanças, 0 dinheiro, em si, não tem sido um grande problema entre os cônjuges, indo ao encontro dos achados do estudo de Féres-Carneiro, Ziviani \& Magalhães (2011), quando afirmam que o dinheiro não parece ser o grande vilão dos relacionamentos.

As consequências positivas relacionadas às situações de infidelidade financeira revelam que os participantes dessa pesquisa demonstraram bom grau de concordância em relação ao gerenciamento do dinheiro, tanto realizado em conjunto, como em relação às despesas pessoais do(a) parceiro(a). É possível conjecturar que esses casais têm conseguido lidar bem com o manejo do dinheiro do casal e que isso tem refletido na harmonia e até satisfação dos mesmos com o relacionamento, como relataram Boyle (2012) e Vogler et. al. (2008) em seus estudos, quando afirmaram que homens e mulheres se mostram mais satisfeitos com a vida familiar quando tomam decisões em conjunto do que aqueles que tomam suas decisões financeiras individualmente.

Estudos anteriores (Mosmann \& Falcke, 2011; Papp, Cummings, \& Goeke-Morey 2009) reconheceram o dinheiro como um dos principais motivos de conflitos conjugais, porém nesse estudo, esse conflito não 
ficou evidente. Devemos, portanto, considerar possíveis características específicas desta amostra que possam ter contribuído para o alcance desses resultados como uma distribuição homogênea de renda no nível socioeconômico médio e a preponderância de um manejo compartilhado das finanças conjugais.

\section{Considerações finais}

Diante da literatura a respeito do tema proposto nesse artigo, percebemos a diferença em relação aos dados encontrados com os resultados apontados por pesquisas anteriores. Preponderam na literatura estudos que indicam que o dinheiro é um dispositivo de conflito entre os cônjuges. Todavia, neste estudo, esses conflitos não ficam evidentes, parecendo que essa amostra foi constituída por casais que convivem harmoniosamente no quesito gerenciamento das finanças. Os resultados desse estudo corroboraram achados de uma única pesquisa prévia que também identificou baixos níveis de conflitos relacionados às finanças. Além disso, também contrariam o pressuposto de que conflitos financeiros estariam mais relacionados ao manejo do dinheiro do que a quantidade, uma vez que se observou associação entre infidelidade financeira e renda.

Como limitações deste estudo, é preciso levar em consideração a possibilidade dos resultados terem sido enviesados pelas características da amostra, já que os participantes se enquadraram em um nível socioeconômico médio. Também, deve-se considerar a possibilidade de que os participantes tenham respondido 0 instrumento baseados na desejabilidade social, querendo não se expor em relação a esse assunto que ainda pode ser considerado tabu.

Acredita-se que o presente estudo teve o mérito de contribuir para uma maior reflexão sobre o assunto e para propor a versão inicial de um instrumento que possa avaliar o manejo do dinheiro pelo casal, já que não foram encontrados na literatura instrumentos disponíveis em relação a esse tema. Todavia, ressalta-se a importância de que estudos futuros possam validar o instrumento, e que se possa, dessa forma, instigar novas e importantes discussões sobre esse tema que ainda é pouco debatido.

Com os resultados desse estudo, que indicam a correlação entre renda e situações de infidelidade financeira, percebemos a necessidade de, em pesquisas subsequentes, mensurar a situação de endividamento dos casais e os diferentes níveis socioeconômicos, pois seriam variáveis que poderiam contribuir para uma melhor compreensão do fenômeno. 


\section{Referências}

Archuleta, K. L. (2013). Couples money, and expectations: negotiating financial management roles to increase relationship satisfaction. Marriage \& Family Review, 49(5), 391-411.

Atwood, J.D. (2012). Couples and Money: The Last Taboo. The American Journal of Family Therapy, 40, 1-19. doi: 10.1080/01926187.2011.600674

Boyle, J. (2012). Shared money, less conflict, stronger marriages: The relationship between money ownership perceptions, negative communication, financial satisfaction, marital satisfaction and marital instability. Tese de Doutorado, Universidade Estadual do Kansas, Kansas, Estados Unidos. Disponível em: state.edu/dspace/handle/2097/13638. https://krex.k20/08/2015).

Burgoyne, C. B., Reibstein, J., Edmunds, A., \& Dolman, V. (2007). Money management systems in early marriage: factors influencing change and stability. Journal of Economic Psychology, 28(1), 214-228. doi: 10.1016/j.joep.2006.02.003

Cardoso, F., \& Lima, G. T. (2006). Diagnosticando patologias monetárias: seus impactos sobre a atividade produtiva na visão de Keynes e Veblen. Estudos Econômicos, 36(2), 293-321. doi: $10.1590 /$ S0101-41612006000200005

Cezar-Ferreira, V. A. M. (2007). Família, separação e mediação: uma visão psicojurídica. São Paulo: Editora Método.

Costa, G. P. (2007). O amor e seus labirintos. Porto Alegre: Artmed.

Falconier, M. K., \& Epstein, N. B. (2010). Relationship satisfaction in Argentinean couples under economic strain: Mediating factors and gender differences in a dyadic stressmodel. Journal of Social and Personal Relationships, 27, 781-799. doi: $10.1177 / 0265407510373260$

Féres-Carneiro, T., Ziviani, C., \& Magalhães, A. S. (2011). Arranjos amorosos contemporâneos: sexualidade, fidelidade e dinheiro na vivência da conjugalidade. In: T. Féres-Carneiro. (Org.). Casal e família: conjugalidade, parentalidade e psicoterapia. (pp 43-60). São Paulo: Casa do Psicólogo.

Hardie, J. H. \& Lucas, A. (2010). Economic factors and relationship quality among young couples: Comparing cohabitation and marriage. Journal of Marriage and Family, 72, 1141-1154. doi: 10.1111/j.1741-3737.2010.00755.x

Instituto Brasileiro de Geografia e Estatística - IBGE. (2011). Pesquisa Nacional por Amostra de Domicílios - PNAD. Recuperado de http://www.ibge.gov.br/home/estatistica/populacao/trabalhoer endimento/pnad2011/ 
Lauer, S. R. \& Yodanis, C. (2011). Individualized Marriage and the Integration of Resources. Journal of Marriage and Family 73, 669-683. doi: $10.1111 /$ j.1741-3737.2011.00836.x

National Endowment for Financial Education (2010). Financial deception with partners. Recuperado de http://www.nefe.org/press-room/news/admitting-to-financialdeceptions.aspx

Mills, R. J., Grasmick, H. G., Morgan, C. S., \& Wenk, D. (1992). The effects of gender, family satisfaction, and economic stress on psychological well-being. Family Relations, 41, 440-446.

Moore, K. B. \& Palumbo, M. G. (2009). The finances of American household in the past three recessions: evidence from the Survey on Consumer Finances. Washington, DC: Division of Research \& Statistics and Monetary Affairs, Federal Reserve Board. Recuperado de http://www.federalreserve.gov/pubs/feds/2010/201006/20100 6pap.pdf

Mosmann, C., \& Falcke, D. (2011). Conflitos conjugais: motivos e frequência. Revista da SPAGESP - Sociedade de Psicoterapias Analíticas Grupais do Estado de São Paulo, 12(2), 5-16.

Papp, L. M., Cummings, E. M., \& Goeke-Morey, M. C. (2009). For richer, for poorer: Money as a topic of marital conflict in the home. Family Relations, 58, 91-103. doi: 10.1111/j.17413729.2008.00537.x

Pahl, J. (1989). Money and marriage. London: MacMillan.

Pergher, N. K. (2010). Variáveis que devem ser consideradas na avaliação da qualidade do relacionamento conjugal. Revista Perspectivas, 1(2), 116-129.

Perlin, G. D. B. (2006). Casamentos contemporâneos: um estudo sobre os impactos da interação família-trabalho na satisfação conjugal. (Tese de Doutorado, Universidade de Brasília). Recuperado de http://repositorio.unb.br/handle/10482/9274

Robila, M., \& Krishnakumar, A. (2005). Effects of economic pressure on marital conflict in Romania. Journal of Family Psychology, 19, 246-251. doi: 10.1037/0893-3200.19.2.246

Rose, G. M., \& Orr, L. M. (2007). Measuring and exploring symbolic money meanings. Psychology and Marketing, 24(9), 743-761. doi: 10.1002/mar.20182

Smock, P. J., Manning, W. D., \& Porter, M. (2005). Everything's there except money: How money shapes decisions to marry among cohabitors. Journal of Marriage and Family, 67, 680-696. doi: 10.1111/j.1741-3737.2005.00162.x

Vogler, C., Lyonette, C., \& Wiggins, R. D. (2008). Money, power and spending decisions in intimate relantionships. The Sociological Review, 56(1), 2008. doi: 10.1111/j.1467-954X.2008.00779.x 
White, L., \& Rogers, S. J. (2000). Economic circumstances and family outcomes: A review of the 1990s. Journal of Marriage and the Family, 62, 1035-1051. doi: 10.1111/j.17413737.2000.01035.x

Wiik, K. A., Bernhardt, E., \& Noack, T. (2010). Love or Money? Marriage intentions among young cohabitors in Norway and Sweden. Acta Sociologica, 53(3), 269-287. doi: $10.1177 / 0001699310374488$

Xavier, V. R. (2013). Género y dinero: múltiples matices en la relación de pareja. Psicologia em Estudo, 18(2), 363-369.

\section{Endereço para correspondência \\ Jeniffer Harth}

Universidade do Vale do Rio dos Sinos

Avenida Unisinos, 950, CEP 93022-750, São Leopoldo - RS, Brasil

Endereço Eletrônico: jeni.psico@yahoo.com.br

\section{Clarisse Pereira Mosmann}

Universidade do Vale do Rio dos Sinos

Avenida Unisinos, 950, CEP 93022-750, São Leopoldo - RS, Brasil

Endereço Eletrônico: clarissepm@unisinos.br

\section{Denise Falcke}

Universidade do Vale do Rio dos Sinos

Avenida Unisinos, 950, CEP 93022-750, São Leopoldo - RS, Brasil

Endereço Eletrônico: dfalcke@unisinos.br

Recebido em: 13/04/2015

Reformulado em: 25/08/2015

Aceito para publicação em: 20/09/2015

\section{Notas}

* Psicóloga. Mestre em Psicologia pela Universidade do Vale do Rio dos Sinos.

** Psicóloga. Doutora em Psicologia. Professora do Curso e do Programa de PósGraduação em Psicologia da Universidade do Vale do Rio dos Sinos.

*** Psicóloga. Doutora em Psicologia. Professora do Curso e do Programa de PósGraduação em Psicologia da Universidade do Vale do Rio dos Sinos. 